\title{
Game Analysis of Regional Innovation System Based on Circular Economy
}

\author{
Cao Qian \\ College of Finance, Shandong University of Finance and Economics, Jinan Shandong \\ 29890556@qq.com
}

\begin{abstract}
Keywords: circular economy; regional innovation system; Game; government mechanism Abstract.Regional innovation system and circular economy are the important means to solve the problems between economic development and resources and environment. However, there are still some contradictions between them currently. Therefore, this paper studies the construction of regional innovation system in circular economy. Research shows that the construction of the regional innovation system based on the circular economy is difficult to be solved by the market mechanism alone; the functions of the government and other institutions are performed on conditions; The power for the government to build the regional innovation system based on the circular economy mainly comes from its ability to serve the community and considerations on its long-term interests. The innovation of this paper is that it constructs the game model between regional innovation and circular economy and governments based on the Cournot model and Stackelberg model.
\end{abstract}

\section{Introduction}

Innovation is the soul of national progress, and the inexhaustible motive force of the country's prosperity. The 17th CPC National Congress even takes "improve the ability of independent innovation, build an innovative country" as national strategy. The regional innovation system is an important part of the national innovation system. The perfect and dynamic regional innovation system will lay a solid foundation for the realization of the goal of building an innovative country. In 30 years of reform and opening up, China's economy has made brilliant achievements, but a problem that can not be ignored is that China's rapid economic growth is mainly driven by huge investment and a lot of energy consumption. This extensive development model not only is unsustainable, but also causes serious ecological and environmental problems. In this case, the circular economy model with the feature of "resource - product - renewable resources" has been increasingly paid attention. If the regional innovation system and circular economy can develop in a coordinated way, the problem between economic development and resources and environment can be fundamentally resolved. But things go athwart. The traditional regional innovation system is a "double-edged sword". While promoting the development of circular economy, it also sets a hindrance for the further development of circular economy. For example, in the traditional regional innovation system, many of the principles and patterns of technology is built on the basis of physics and chemistry, and use chemical and physical principles to change the external appearance of nature, which will inevitably consume a lot of resources and break the original ecological, social and economic balance. And what's more, the traditional regional innovation system gives priority to economic efficiency, which also sets obstacles to the in-depth development of the circular economy.

Theorists have also recognized this problem, and the research on this problem has been deepened in recent years. Previous studies mainly include the following aspects. First, research on the mechanism. For example, Wang Yinghua(2016) reveals the ecological evolution mechanism of regional strategic emerging industry innovation from the three aspects of evolutionary driving force, evolution process and upgrading conditions. Liu Lu (2015) constructs the cooperative innovation mechanism of circular economy park based on knowledge sharing. Second, research on influence factors. For example, Rennings and Zwick et al. (2011) have pointed out that the driving force of innovation ecologization is influenced by factors such as national regulation, user needs, access to new markets; Jackson (2012) argues that innovative ecosystems include a basic research-driven knowledge system and a 
market-driven business system, specifically affected by actors, entities and intangible assets. Third, research on the evaluation. For example, Li Guangpei (2014) studies regional innovation performance evaluation from the perspective of circular economy. Fourth, research on policy recommendations. For example, Alex (2009) takes green car as an example, and shows that in the construction of innovative ecological environment, the government's environmental policy plays a guiding and promoting role, and the government should strengthen the construction and improvement of environmental policy. But there are few studies conducted from the perspective of game. Therefore, this paper studies the regional innovation system in the view of circular economy from the perspective of game theory, hopes to explain the problem deeply and improve the basic theory of circular economy and regional innovation system, providing reference for the relevant departments on decision-making.

\section{The game between regional innovation system and circular economy}

The construction of regional innovation system based on circular economy is not the responsibility of one enterprise. Because circular economy and regional innovation systems both are complex systems, the virtuous circle of the system requires the participation of each subject in the region. Therefore, the study of regional innovation system based on circular economy can have following assumptions: when every enterprise adopt regional innovation system based on circular economy, the marginal cost of unit product is reduced, that is, the regional innovation system based on circular economy can be realized; but if there is one enterprise not cooperating, then regional innovation system based on the circular economy can not be achieved.

The game of two enterprises.Assume that there are only two enterprises 1 and 2 in the area. When both two enterprises do not take innovation based on circular economy, their marginal cost is $c$; when both two enterprises have adopted innovation based on circular economy, their marginal $\operatorname{cost}$ is $c_{1}$; when an enterprise takes innovation based on circular economy, the other enterprise does not take the innovation based on the circular economy, the marginal cost of enterprise which takes innovation is $c_{2}$, the marginal cost of the enterprise which doesn't take innovation is $c$. here has $c_{2}>c>c_{1}$. 1)Both enterprises have taken innovation based on circular economy

When both two enterprises have taken innovation strategy based on the circular economy, that is, the two enterprises cooperate with each other, fitting static Cournot model. According to the previous solution, it can be concluded:

$$
\begin{aligned}
& q_{1}=q_{2}=\frac{1}{3}\left(a-c_{1}\right) \\
& u_{1}=u_{2}=\frac{1}{9}\left(a-c_{1}\right)^{2}
\end{aligned}
$$

2)Neither of the two enterprises takes the innovation strategy based on circular economy When neither of the two enterprises takes the innovation strategy based on circular economy, the equilibrium yield and benefit are:

$$
\begin{aligned}
& q_{1}=q_{2}=\frac{1}{3}(a-c) \\
& u_{1}=u_{2}=\frac{1}{9}(a-c)^{2}
\end{aligned}
$$

3)Enterprise 1 takes the innovation strategy based on circular economy, enterprise 2 chooses not take the strategy 
When the enterprise 1 takes the innovation strategy based on the circular economy, and the enterprise 2 does not adopt the innovation strategy based on the circular economy, the equilibrium quantity and benefit of the two enterprises are:

$$
\begin{aligned}
& q_{1}=\frac{1}{3}\left(a+c-2 c_{2}\right) \quad q_{2}=\frac{1}{3}\left(a+c_{2}-2 c\right) \\
& u_{1}=\frac{1}{9}\left(a+c-2 c_{2}\right)^{2} \quad u_{2}=\frac{1}{9}\left(a+c_{2}-2 c\right)^{2}
\end{aligned}
$$

4)Enterprise 1 does not take the innovation strategy based on circular economy, and enterprise 2 takes the strategy

When enterprise 1 does not adopt the innovation strategy based on the circular economy, and enterprise 2 takes the innovation strategy based on the circular economy, the equilibrium quantity and benefit of the two enterprises are:

$$
\begin{aligned}
& q_{1}=\frac{1}{3}\left(a+c_{2}-2 c\right) \quad q_{2}=\frac{1}{3}\left(a+c-2 c_{2}\right) \\
& u_{1}=\frac{1}{9}\left(a+c_{2}-2 c\right)^{2} \quad u_{2}=\frac{1}{9}\left(a+c-2 c_{2}\right)^{2}
\end{aligned}
$$

Do benefit matrix analysis of game under the above four conditions and the results is as shown below:

\begin{tabular}{|c|c|c|c|}
\hline \multirow{2}{*}{\multicolumn{2}{|c|}{}} & \multicolumn{2}{|c|}{ Enterprise 2 } \\
\cline { 3 - 4 } & cooperation & not cooperation \\
\hline \multirow{2}{*}{ Enterprise 1 } & cooperation & $\frac{1}{9}\left(a-c_{1}\right)^{2}, \frac{1}{9}\left(a-c_{1}\right)^{2}$ & $\frac{1}{9}\left(a+c-2 c_{2}\right)^{2}, \frac{1}{9}\left(a+c_{2}-2 c\right)^{2}$ \\
\cline { 2 - 4 } & $\begin{array}{c}\text { not } \\
\text { cooperation }\end{array}$ & $\frac{1}{9}\left(a+c_{2}-2 c\right)^{2}, \frac{1}{9}\left(a+c-2 c_{2}\right)$ & $\frac{1}{9}(a-c)^{2}, \frac{1}{9}(a-c)^{2}$ \\
\hline
\end{tabular}

Fig.1 Game graph of two enterprises' product innovation

Because $c_{2}>c>c_{1}$, so ${\frac{1}{9}(a-c)^{2}}^{\frac{1}{9}\left(a+c-2 c_{2}\right)^{2}}$, so, ( not cooperation, not cooperation) is a pure strategic Nash equilibrium of the game under any condition. When $2 c-c_{1}-c_{2} \geq 0$, (cooperation, cooperation) is the pure strategic Nash equilibrium of the game. Two companies' game in this area can not represent the behavior of the entire region. Next, the author will discuss the game from the perspective of entire region.

The game of $\mathbf{n}$ enterprises.Suppose there are $\mathbf{n}$ enterprises in the region, and we construct the game model of one enterprise and other n-1 enterprises in the region. And assume that the probability that an enterprise does not adopt the innovation strategy based on the circular economy is $p$, and the probability of taking such strategy is $1_{-} p$; and the probability that the $\mathrm{n}-1$ enterprises do not take the innovation strategy based on the circular economy is $p^{n-1}$, and the probability of taking such strategy is $1-p^{n-1}$.

The overall expectation of enterprise 1 takes the innovation strategy based on circular economy is:

$E U_{1 H Z}=\frac{1}{9}\left(a-c_{1}\right)^{2}\left(1-p^{n-1}\right)+\frac{1}{9}\left(a+c-2 c_{2}\right)^{2} p^{n-1}$

The overall expectation of enterprise 1 does not take the strategy is: 


$$
E U_{1 B H Z}=\frac{1}{9}\left(a+c_{2}-2 c\right)^{2}\left(1-p^{n-1}\right)+\frac{1}{9}(a-c)^{2} p^{n-1}
$$

Let $E U_{1 H Z}=E U_{1 B H Z}$

Achieve the result:

$$
p^{n-1}=\frac{\left(2 a+c_{2}-c_{1}-2 c\right)\left(2 c-c_{1}-c_{2}\right)}{\left(2 a+c_{2}-c_{1}-2 c\right)\left(2 c-c_{1}-c_{2}\right)+4\left(a-c_{2}\right)\left(c_{2}-c\right)}
$$

$$
\begin{aligned}
& \text { Namely } \begin{array}{l}
p=\left[\frac{\left(2 a+c_{2}-c_{1}-2 c\right)\left(2 c-c_{1}-c_{2}\right)}{\left(2 a+c_{2}-c_{1}-2 c\right)\left(2 c-c_{1}-c_{2}\right)+4\left(a-c_{2}\right)\left(c_{2}-c\right)}\right]^{\frac{1}{n-1}} . \\
\text { Because }
\end{array} \quad<\frac{\left(2 a+c_{2}-c_{1}-2 c\right)\left(2 c-c_{1}-c_{2}\right)}{\left(2 a+c_{2}-c_{1}-2 c\right)\left(2 c-c_{1}-c_{2}\right)+4\left(a-c_{2}\right)\left(c_{2}-c\right)}<1
\end{aligned}
$$

When $n \rightarrow \infty$, the probability $p$ of enterprise 1 not taking the innovation strategy based on the circular economy approaches 1 .

In reality, there are many enterprises in the region. The larger the region is, the more enterprises it has. So the probability that enterprises do not take the innovation strategy based on the circular economy should be very large. Therefore, it is difficult to establish a regional innovation system based on circular economy relying solely on the market mechanism from the perspective of market.

\section{The game between regional innovation and circular economy after the introduction of government mechanisms}

Earlier the author analyses that it is difficult to establish a regional innovation system based on circular economy in the region relying solely on the market mechanism. So we introduce the mechanism of government - means such as constraint supervision or policy support. Constraint supervision is a kind of punishment mechanism, punishing enterprises in the region which do not take the innovation strategy based on circular economy, which is equivalent to increasing the cost of the enterprise; and policy support mechanism is a reward mechanism, rewarding enterprises which takes the innovation strategy based on the circular economy in the region, which is equivalent to reducing the cost of the enterprise.

Assume that it takes the government one year to find enterprises that do not adopt the innovation strategy based on circular economy, and it also takes government one year to punish such enterprises, and the result of punishment is that the marginal cost of enterprises which does not take the strategy increases to $c_{3}$. And assume the discount factor is $\delta$. Here, $c^{c}$ is the marginal cost when all enterprise do not take innovation strategy based on circular economy; ${ }^{c_{1}}$ is the marginal cost when all enterprise take innovation strategy based on circular economy; as long as there is enterprise not adopting innovation strategy based on circular economy, the unit product's marginal cost of enterprises which take the strategy is $c_{2}$. The relationship between these marginal costs is $c_{3}>c_{2}>c>c_{1}$.

The income of enterprise which does not take innovation strategy based on circular economy is: $u_{N O}=\frac{1}{9}\left(a+c_{2}-2 c\right)^{2}+\delta \frac{1}{9}\left(a+c_{3}-2 c\right)^{2}+M$

$\mathrm{M}$ is the sum of enterprises which take innovation strategy based on circular economy from stage 2 to infinite stage. The income of enterprise which takes innovation strategy based on circular strategy from the beginning is : 


$$
u_{Y E S}=\frac{1}{9}\left(a-c_{1}\right)^{2}(1+\delta)+M
$$

Let $u_{Y E S}>u_{N o}$, namely the income of enterprise which takes such strategy is more than the income of enterprise which does not take the strategy.

$$
\frac{1}{9}\left(a-c_{1}\right)^{2}(1+\delta)+M>\frac{1}{9}\left(a+c_{2}-2 c\right)^{2}+\delta \frac{1}{9}\left(a+c_{3}-2 c\right)^{2}+M
$$

simplified as:

$$
\left(2 a-c_{1}-2 c+c_{3}\right)\left(2 c-c_{1}-c_{3}\right) \delta>\left(2 a-c_{1}+c_{2}-2 c\right)\left(c_{1}+c_{2}-2 c\right)
$$

Because $2 a-c_{1}-2 c+c_{3}>0,2 a-c_{1}+c_{2}-2 c>0$, then the conditions precedent of government regulation, binding policy can be divided into several cases:

(1) when $2 c-c_{1}-c_{3} \geq 0$, namely $2 c-c_{1} \geq c_{3}$, it can be derived $2 c-c_{1} \geq c_{3}>c_{2}$, namely $c_{2}+c_{1}-2 c<0$. At this time, $\frac{\left(2 a-c_{1}+c_{2}-2 c\right)\left(c_{2}+c_{1}-2 c\right)}{\left(2 a-c_{1}-2 c+c_{3}\right)\left(2 c-c_{1}-c_{3}\right)}<0$, and the discount factor $\delta$ is generally greater than 0 , so, $\left(2 a-c_{1}-2 c+c_{3}\right)\left(2 c-c_{1}-c_{3}\right) \delta>\left(2 a-c_{1}+c_{2}-2 c\right)\left(c_{1}+c_{2}-2 c\right)$ is automatically true. That is to say, when $2 c-c_{1} \geq c_{3}$, discount factor doesn' t need to be adjusted.

(2)When $2 c-c_{1}<c_{3}$, namely $2 c-c_{1}-c_{3}<0,2 c-c_{1}-c_{2}$ may be less than 0 , or greater than or equal to 0 . So $c_{1}+c_{2}-2 c$ can also be less than 0 , or greater than 0 .

(1) when $c_{1}+c_{2}-2 c$ is greater than 0 ,

$\left(2 a-c_{1}-2 c+c_{3}\right)\left(2 c-c_{1}-c_{3}\right) \delta>\left(2 a-c_{1}+c_{2}-2 c\right)\left(c_{1}+c_{2}-2 c\right)$ does not have solution;

(2) when $c_{1}+c_{2}-2 c$ is less than 0 , namely $c_{2}<2 c-c_{1}$, plus the condition $2 c-c_{1}<c_{3}$, so get the total conditions : $c_{2}<2 c-c_{1}<c_{3}$.

Thus, when $c_{2}<2 c-c_{1}<c_{3}$, the discount factor of government regulation and constrains should meet the condition:

$\delta<\frac{\left(2 a-c_{1}+c_{2}-2 c\right)\left(c_{2}+c_{1}-2 c\right)}{\left(2 a-c_{1}-2 c+c_{3}\right)\left(2 c-c_{1}-c_{3}\right)}$.

By summing up the above conclusions, it can be drawn that if the government wants to play a role in the construction of regional innovation system based on circular economy, it needs to meet the conditions and inspiration:

First, in the construction of regional innovation system based on circular economy, the government mainly needs to adjust the value of $c_{3}$. The measures it can take include supervision and restraint of enterprises which do not adopt innovation mode based on circular economy, or award and support for enterprises which adopt such mode. The discount factor is determined by the market interest rate. Under normal circumstances, it is decided by the market mechanism. In countries which the government determines market interest rate, the government can meet conditions for the region to construct innovation system based on circular economy through adjustment of market interest rate.

Second, when the government's measures are in line with the condition $2 c-c_{1} \geq c_{3}$, the government's strategy can play a role without adjusting the discount factor. 
Third, when the government' $\mathrm{s}$ measures are under the condition of $c_{2}<2 c-c_{1}<c_{3}$, the government needs to adjust the discount factor to meet $\delta<\frac{\left(2 a-c_{1}+c_{2}-2 c\right)\left(c_{2}+c_{1}-2 c\right)}{\left(2 a-c_{1}-2 c+c_{3}\right)\left(2 c-c_{1}-c_{3}\right)}$. When the discount factor can not be adjusted, whether the measures formulated by the government are effective depends on whether it can meet $c_{2}<2 c-c_{1}<c_{3}$ or the equation $\left(2 a-c_{1}-2 c+c_{3}\right)\left(2 c-c_{1}-c_{3}\right) \delta>\left(2 a-c_{1}+c_{2}-2 c\right)\left(c_{1}+c_{2}-2 c\right)$ has solution.

Fourth, when $c_{1}+c_{2}-2 c>0$, all the measures formulated by government will not take effect, that is, the failure of government functions.

\section{The power source for government to participate in regional innovation system based on circular economy}

Earlier, we analyzes the government intervention, can promote the construction of regional innovation system based on circular economy under certain conditions. Then, what is the power source of government intervention? The author will use the game theory to analyze this problem below.

We take the government as a rational economic man, the government's income is reflected in the support of the masses, and the masses support government for its performance, that is to stimulate the local economic development and protect the interests of the people. Of course, the government needs to be clear about these. We' 11 discuss this issue in short and long term.

In the short term, the key that whether the government can get support and whether the leader can be promoted is the economic growth rate. China is like that before. In this case, the government does everything possible to seek development. Regional innovation, of course, can greatly improve the local productivity, and access to higher GDP growth figures; and the cost of regional innovation based on circular economy is high in the early stage. So the relative economic growth rate is certainly less than economic growth rate in areas which only conducts regional innovation. Therefore, when the two governments of the same level play complete information static game, (not support, not support) must be their pure strategy Nash equilibrium.

In the long term, the government not only needs to consider the economic development, but also needs to care about the people's living environment. Because when people's living standards develop to a certain extent, economic growth is less effective to them, and they will become increasingly concerned about the environment near them, because the deterioration of the environment will affect people's health. So deterioration of the environment will reduce the satisfaction of the masses, and their support for government will decline. Therefore, the government's long-term decision-making should support regional innovation system construction based on circular economy.

Therefore the government is caught in the contradiction of long-term decision-making and short-term decision-making. How can the government have the incentive to support the construction of regional innovation system based on circular economy? The key is to consider the evaluation of government from in the long term, and the scope of evaluation should also be comprehensive, not only having the economic growth, but also improving the quality of economy and people's living environment.

\section{Conclusion and deficiency}

Through the above analysis, the following conclusions can be drawn: from the perspective of rational economic man, it is difficult to construct regional innovation system based on circular economy solely relying on market mechanism. It needs to get support from government and other means; the supervision and incentive functions of government and other institutions is conditional; the government's power to construct regional innovation system based on circular economy mainly comes from its function to serve society and the consideration of its own long-term interest. Therefore, 
in order to give play to government' s function on promoting the construction of regional innovation system based on circular economy, we must conduct a long-term, systematic assessment towards government.

The deficiency of the research of the paper lies in following aspects: first, this paper' $\mathrm{s}$ analysis of game between circular economy and regional innovation system is conducted based on complete rationality and complete information, and the reaction of enterprises and regional is immediate optimal response. But in reality, most enterprises and regions do not have complete information and complete rationality. Their response is also not the immediate adjustment of the optimal strategy. They need a learning process. It can be said that the enterprise's response to innovation and recycling economy production mode is an evolutionary process that requires gradual adjustment. Second, treat government, regional innovation system as complete rational "economic man" like enterprises. But the main function of government lies in service, so the regional innovation system should also have a multiple target system. Third, treat regional innovation problem as a cost problem, and ignore the impact of other factors; moreover, the consumption that the cost for enterprise to implement circular economy rises first and falls later, needs to be seriously considered.

\section{Acknowledgments}

This work was financially supported by Post funded project of National Social Science Foundation "The modern theory and policy research of of environmental economics " (11FJY007). and Shandong science and technology development plan project"Study on the environmental law enforcement system in Shandong Province" (2014GGH222001).

\section{References}

[1] ALEX C, PETER H, et al. Consumer support for environmental policies: An application to purchases of green cars [J]. Ecological Economies, 2009, (5): 2078-2086.

[2] Jackson D J. What Is an Innovation Ecosystem? [R]. National Science Foundation, Arlington, VA, 2012: $2-10$

[3] Rennings K, Zwick T. The employment impact of cleaner production on the firm level empirical evidence from a survey in five European countries [Z]. ZEW Discussion Paper, 2011: 1-8.

[4] Li Guangpei, Wu Jinhua, Zhu Suzhen. Study on Regional Innovation Performance Evaluation From the Perspective of Circular Economy[J]. Logistics Engineering and Management .2014 (9): 165-169. (In Chinese)

[5] Liu Lu. Research on Cooperative Innovation Mechanism of Circular Economy Park Based on Knowledge Sharing[D]. Southwest University of Science and Technology Master Thesis. 2015. (In Chinese)

[6] Wang Yinghua. Research on Government Science and Technology Support Mechanism for Regional Strategic Emerging Industry Innovation Ecologicalization[D]. Harbin University of Science and Technology Doctoral Thesis. 2016.(In Chinese) 
ATLANTIS
PRESS 